\title{
Posterior reversible encephalopathy syndrome with spinal cord involvement
}

\author{
Fabiola Serrano ${ }^{1}$, Marie-Cécile Henry-Feugeas ${ }^{2}$, Emmanuelle Vidal-Petiot ${ }^{3}$ and Philippa C Lavallee ${ }^{1,4 *}$ \\ ${ }^{1}$ Department of Neurology and Stroke Centre, Bichat-Claude Bernard Hospital, France \\ ${ }^{2}$ Department of Radiology, Neuroradiology Unit, France \\ ${ }^{3}$ Department of Physiology, Bichat-Claude Bernard Hospital, France \\ ${ }^{4}$ INSERM U-698, Denis Diderot University and Medical School, Bichat-Claude Bernard Hospital, France
}

\section{Introduction}

Posterior reversible encephalopathy syndrome (PRES) is a disorder related to an acute impairment of cerebral flow autoregulation that causes brain hyperperfusion and blood-brain barrier breakdown, leading to vasogenic edema affecting typically the posterior part of the brain usually related to acute severe hypertension [1]. Usual clinical presentation includes headaches, vomiting, encephalopathy, visual blurring and seizures. Diagnosis is confirmed by brain MRI showing vasogenic edema with usually a bilateral parieto-occipital pattern although brain oedema could affect other parts of the brain. Ten years ago, a case of reversible edema of the spinal cord has been reported in a patient with PRES associated to malignant hypertension (PRES-SCI, PRES with spinal cord involvement).

\section{Case report}

A 27-year-old man with no significant medical history, no medication or drug abuse presented at the emergency department with a 10-day history of altered general condition, abdominal pain, vomiting, headache, and visual blurring. The patient was alert, general examination was normal as well as neurological status except fundoscopy examination that showed a grade IV hypertensive retinopathy, defining malignant hypertension. Blood pressure was 255/158 mmHg. Hematologic tests at presentation revealed bicytopenia (haemoglobin 9.8gr/dL, platelet $51000 / \mathrm{mm} 3$ ), presence of schizocytes, undetectable haptoglobin in favour of a microangiopathy associated with malignant hypertension. ADAMTS 13 was moderately decrease (51\%). Serum creatinine was increased $(227 \mu \mathrm{mol} / \mathrm{L})$ with presence of proteinuria $(0.47 \mathrm{~g} / 24 \mathrm{~h})$. Other laboratory results were unremarkable.

Blood pressure was rapidly controlled with intravenous infusion of nicardipine. Twenty-four hours later, whereas blood pressure was normalized, he woke up with left leg weakness. Neurological examination found partial motor deficit of the left leg with pyramidal signs limited to the lower limbs, deep and superficial sensory decrease with a T12 level, urine retention and erectile dysfunction. Brain MRI showed T2 and fluid-attenuated inversion recovery (FLAIR) hyperintensity of the medulla prompting MRI of the spinal cord that showed central T2 hyperintensity suggesting a transverse myelopathy extending from the bulb to the lumbar portion of the spinal cord. Medulla and spinal cord lesions did not show any diffusion restriction lesion, in good agreement with a vasogenic oedema (Figure 1). Lumbar puncture was normal, including absence of oligoclonal band. Extensive immunologic and infectious workup was negative. Clinical and

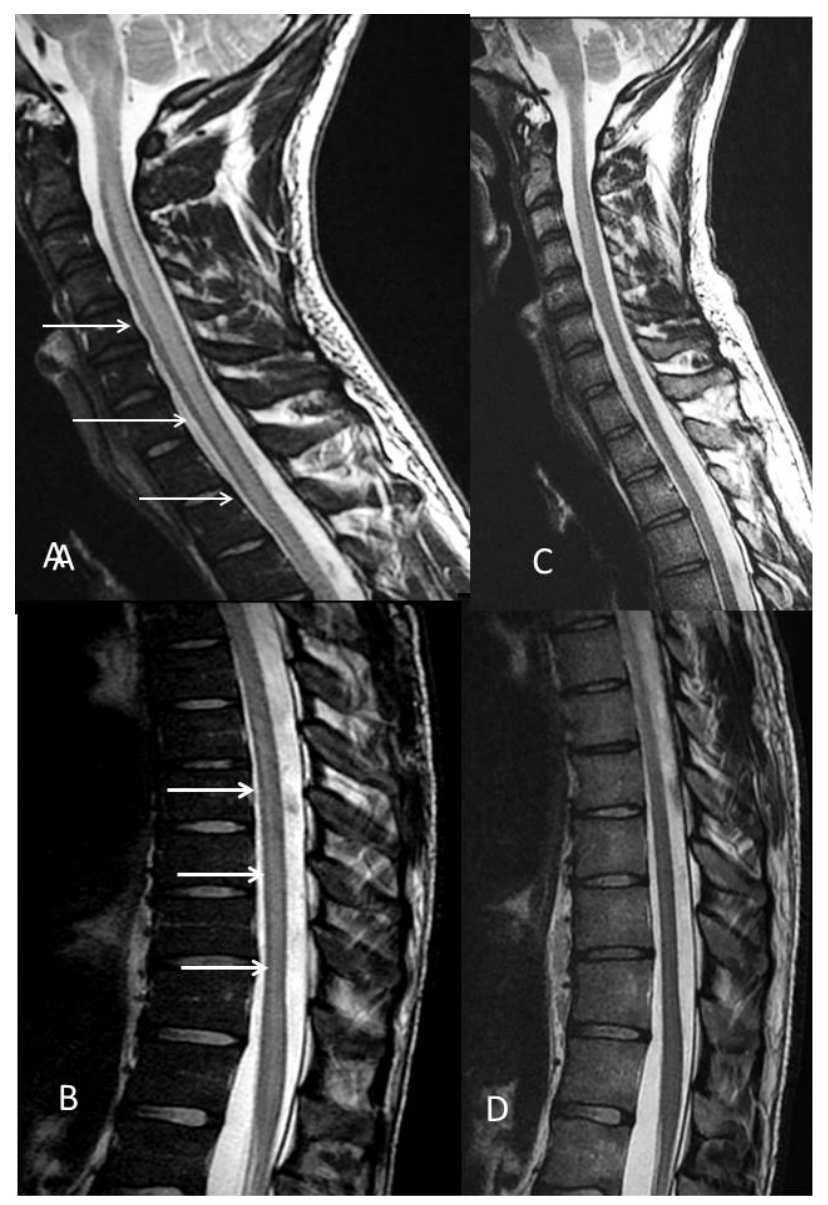

Figure 1. Sagittal T2 spinal cord. A, B: Longitudinally extensive intramedullary centrally located hyperintensity in the medulla and the entire spinal cord (arrows). C, D: Normalization of the spinal cord at one month

${ }^{\star}$ Correspondence to: Philippa C Lavallee, Department of Neurology and Stroke Centre, Bichat University Hospital, 46 rue Henri Huchard, 75018 Paris, France, Tel: +33140258726, E-mail: philippa.lavallee@aphp.fr

Key words: malignant hypertension, myelopathy, posterior reversible encephalopathy

Received: September 11, 2020; Accepted: September 21, 2020; Published: September 29, 2020 
radiological features have resolved at one month except the persistence of dysuria (Figure 1).

\section{Discussion}

PRES-SCI presentation is slightly different with the classical PRES (c-PRES) [2-17]. Patients with PRES-SCI 2-23 seems to be younger than those within c-PRES with male predominance. Conversely to c-PRES, PRES-SCI have only been reported with severe hypertension and not with toxic or medications. PRES-SCI can occur in isolation or be associated with brain involvement. MRI lesions are distributed according to a cranio-caudal gradient, medulla oblongata and cervical spinal cord are always involved, whereas thoracic spine seems to be involved in about $60 \%$ of the cases, and whole spine oedema in about $25 \%$ of reported cases. A striking finding is the clinico-radiological dissociation between severe, extensive transverse myelitis and the absence or minor medullary signs. Symptoms resolved with no blood pressure lowering therapy in contrary to other causes of transverse myelitis. This fairly benign prognosis is an important point in order to reassure the patient and avoid useless treatment such as corticosteroid treatment (a standard treatment for myelitis). Finally, as the majority of patients have no or only subtle medullary signs, it is possible that this syndrome is more frequent than what has been reported so far.

PRES related to acute hypertension is supposed to be related to the absence of normal adaptative vasoconstrictive response of brain arterioles in response to an increase of blood pressure above the range of cerebral blood flow autoregulation. Hyperperfusion of arterioles leads to blood-brain barrier a breakdown and subsequent vasogenic edema. Cerebral posterior circulation vascularizing posterior area of the brain, cerebellum, brainstem and spine particularly affected in PRES have a reduced density of sympathetic innervation, implicated in cerebral blood flow regulation.

\section{Conclusion}

PRES-SCI is a rare clinical presentation of PRES sharing many clinicoradiological features with c-PRES, with a benign neurological prognosis and associated with malignant hypertension. Medullary symptoms are often absent despite extensive edema of the spine.

\section{References}

1. Fugate JE, Rabinstein AA (2015) Posterior reversible encephalopathy syndrome: clinical and radiological manifestations, pathophysiology, and outstanding questions. Lancet Neurol 14: 914-925. [Crossref]
2. Milia A, Moller J, Pilia G, Mascia MG, Marchi P, et al. (2008) Spinal cord involvement during hypertensive encephalopathy: clinical and radiological findings. J Neurol 255 : 142-143. [Crossref]

3. Chen TH, Lin WC, Kao WT, Tseng CH, Tseng YW (2017) Posterior Reversible Encephalopathy Syndrome with Spinal cord involvement in children: clinicoradiologic findings and a retrospective comparison between adult and pediatric patients. $J$ Child Neurol 32: 112-119.

4. Liu L, Dai D, Cao F, Zhang L, Wang X (2019) Posterior reversible encephalopathy syndrome with spinal cord involvement but without hemisphere lesions. Medicine 98: e13649. [Crossref]

5. Briganti C, Caulo M, Notturno F, Tartaro A, Uncini A (2009) Asymptomatic spinal cord involvement in posterior reversible encephalopathy syndrome. Neurology 73: 1507-1508. [Crossref]

6. Gory B, Labeyrie PE, Riva R, Sivan-Hoffmann R, Derex L, et al (2016) Spinal cord involvement in posterior reversible encephalopathy syndrome. J Neuroradiol 43: 5658.

7. Chan PKJ, Tse KS, Fok WSE, Poon WL (2018) First case of neurofibromatosis with reversible encephalopathy syndrome showing spinal cord involvement. Indian J Radiol Imaging 28:161-164. [Crossref]

8. Khokhar HV, Choudhary P, Saxena S, Arif M (2016) Posterior reversible encephalopathy syndrome with spinal cord involvement (PRES-SCI): a case report. Ann Indian Acad Neurol 19: 134-136.

9. Freeman D, Koram A, Gillson N, Aylward SC (2017) Pediatric posterior reversible encephalopathy syndrome with spinal cord involvement due to pheochromocytoma. Pediatr Neurol 77: 92-93. [Crossref]

10. Marrone L, Martins W, Brunelli J, Fussiger H, Carvalhal GF, et al (2016) PRES with asymptomatic spinal cord involvement. Is this scenario more common than we know? Spinal Cord Ser Cases 3:15001. [Crossref]

11. Agarwal H, Sebastian LJD, Gaikwad SB, Garg A, Mishra NK (2015) Spinal cord involvement and contrast enhancement in posterior reversible encephalopathy syndrome. BJR Case Rep 2: 20150326. [Crossref]

12. Pinto W, Souza P, Oliveira A (2015) A reversible cause of longitudinally extensive transverse myelopathy question. J Clin Neurosci 2: 1809-1852.

13. Wu TY, Wei DY, Jordan A, Kenedi C, Smith AD, et al. (2015) Reversible hypertensive encephalomyelopathy-the spinal variant of the posterior reversible encephalopathy. $N Z$ Med J 128: 2865-2868. [Crossref]

14. Hou X, Xu J, Chen Z, Li G, Jiang H (2015) Posterior reversible encephalopathy syndrome with involvement of the cervical cord and medulla: a case report. J Clin Diagn Res 9: CD01-CD02. [Crossref]

15. Elkhider H, Mesraoua B, Ibrahim W, Vattoth S, Abbas S, et al. (2016) Clinical reasoning: a young man with acute encephalopathy, loss of vision, and upper motor neuron signs. Neurology 86: e173-e176. [Crossref]

16. Chen TH, Lin WC, Tseng YH, Tseng CM, Chang TT, et al. (2013) Posterior reversible encephalopathy syndrome in children: case series and systematic review. $J$ Child Neurol 28:1378-1386. [Crossref]

17. Ract I, Poujade A, Carsin-Nicol B, Mouriaux F, Ferre JC (2016) Spinal cord involvement in posterior reversible encephalopathy syndrome (PRES). J Neuroradiol $43: 56-58$.

Copyright: (C2021 Serrano F. This is an open-access article distributed under the terms of the Creative Commons Attribution License, which permits unrestricted use, distribution, and reproduction in any medium, provided the original author and source are credited. 